\title{
Modality Analysis in Melania Trump's and Ivanka Trump's Campaign Speeches in Republican National Convention, July 19th, 2016
}

\author{
Hepie Pionery \& Arina Isti'anah \\ pionery.hepie@gmail.com \& arina@usd.ac.id \\ English Letters Department, Universitas Sanata Dharma
}

\begin{abstract}
Style is a distinctive feature found in language use. One example of language use is a speech. In stylistics, the use of modality in a speech can reveal the speaker's style. Subsequently, a style that is shown through the modality can reflect the speaker's ideology. This study aimed to find out the ideology reflected by the modality of Melania Trump's and Ivanka Trump's campaign speeches. The speeches were delivered at the Republican National Convention last July 19th, 2016. There were two objectives discussed in this study. First is to find out the type of modality employed by Melania Trump and Ivanka Trump in their campaign speeches. Second is to reveal the ideologies reflected by the use of the modality. A stylistic approach was employed to discuss the types of modality to figure out the ideologies reflected. The data were taken by employing population study. From the analysis, it was found out that there were four types of modality employed by Melania Trump's speech: inclination, obligation, potentiality and ability, and probability. In Ivanka Trump's speech, there were five types of modality found: inclination, usuality, potentiality and ability, probability, and obligation. There were two ideologies reflected by the use of modality. The ideologies found in both speeches were similar. Those were commitment and self-promotion. The commitments were proved by the existence of inclination, while self-promotion is proven by the existence of potentiality and ability, and usuality types of modality.
\end{abstract}

Keywords: speech, modality, ideology, stylistics

\section{Introduction}

Style is a unique way of expression of language (Verdonk, 2002: 3). It can be used as a distinctive marker to distinguish one language user to another. As an example, women magazines have different language features compared to men magazines. Language in written and spoken form is different either. Every person has different styles in delivering messages. They can be in the grammatical, lexical, phonological, and other linguistic features. For example, some people may prefer to use certain words which includes slang words, but some do not. It shows that different people have different styles.

The use of style in language is based on certain intentions. Moreover, it can cause effects towards the addressees. Verdonk explains that by using certain style, addressees might be influenced and interested emotionally. It simply can be said that Verdonk argues that language may have power that influences hearer's emotion (2002: 6).

Related to the previous paragraph, it is known that language is widely used in every 
aspect in life. Accordingly, language is crucially needed in politics, for example is in the form of political speeches. Political speech should be made as influential as it can be because it deals with power and ideology. In some situations, members of political party tend to present a speech in a campaign to reflect power in certain societies. Speech is seen as the most effective medium to present goals and purposes easily to the audiences. Through speech, the speaker can deliver and show certain ideology toward the audiences. Then, it must be clear how language and ideology are two inseparable things.

If analyzed, a political speech reflects the speaker's style. According to Gee (2011: 7), "language is always political" and "social goods are the stuff of politics". When language is used, the speakers should be ready to face the possibility to be accepted or denied by the society. In accordance with the fact of how vital language is, it is important for the speakers to manage the speech in order to achieve the goal.

Word choice is one feature that defines the style of a speech managed intentionally. In fact, some parties have their own campaign rules because they realize that the use of proper structures in speech will result the best. This slightly shows language is believed to have a strong effect to the listener or reader. There should be preliminary targets to achieve by delivering the speech. Starting from the explanation before, this study focuses on the use of modality in Melania Trump's and Ivanka Trump's campaign speeches. Modality is "the property refers to the strength with which a particular proposition or statement is endorsed" (Locke, 2004: 47). The statement means that modality really influences the message implied in the sentence. It can change the degree of certainty or truth of the sentence or even the contextual meaning of the sentence.

As an example taken from Lilian (2008), the modality should is able to show different meanings depending on the context. She explains that should may have two meanings. The first meaning is to show an obligation to follow the rule as shown in the sentence
"Egalitarinism, a first cousin and natural companion of collectivism, originally meant that all citizens, without regard to class, race, sex, or any other personal characteristic, should be treated equally by the law of the land" (Gairdner in Lilian, 2008). The second meaning, should is also possible to show desirability as shown in the sentence "A proper federation should not allow the central powers to tax the people directly (Gairdner in Lilian, 2008). That is why, in accordance with the previous paragraph, it is assumed that certain purposes can be revealed from the use of modality in the speeches.

The speeches of Melania Trump and Ivanka Trump on the $19^{\text {th }}$ of July 2016, at the Republican National Convention, has been chosen as the objects of the study because Melania as the wife and Ivanka as the daughter of Donald Trump have the same important roles and responsibilities towards the victory of him as the presidential candidacy of the United States. The speeches are important because they influence the American perspectives towards the candidate of their president.

Seeing how crucial the roles are, how the speakers employ the language to show certain purposes or ideology is interesting to conduct. Specifically, the employment through the modality used in the speeches can reflect certain purposes or ideology (Verdonk, 2002). Since there are two objects in this study, in the end of the analysis, the ideologies reflected by the use of modality in both of the speeches can be figured out.

This study is worth to conduct because the result of the study can be used to see how the use of modality in speeches is crucial to determine the reflection of the ideologies. It will be clearer by comparing two speeches to see if later there are some differences in meaning.

There several studies which are still related to this study that have been conducted previously. The first study is conducted by Isti'anah (2012). She analyzed the speeches of Muammar Qaddafi and Hosni 
Mubarak's political speeches. The objectives of Isti'anah's study are finding out the linguistic features in both speeches and what ideologies are revealed by the use of those linguistic features. From the analysis, Isti'anah found out that high level of modality is used to show rule and obligation. However, a low level of modality was also employed by the speakers to show solidarity.

Another study which is in line with this study is conducted by Bayram (2010). He analyzed a political speech by Recep Tayyip Edorgan, the Turkish Prime Minister, for the period of a debate in the World Economic Forum in Davos in January 2009. Bayram stated that a political speech is bound with certain powers, cultural and/or social background, and social status. In relation to that, by employing Critical Discourse Analysis approach, Bayram attempted to discover the social background and identified of Edorgan revealed through the language use.

Bayram found out that what happens to Edorgan is appropriate with Fairclough's theory. The political speech is actually the projection of his social background and identity. Through the speech, Edorgan can still reflect the nature of his society. It shows that his speech is formed by his ideology.

This study aims at finding out the types of modality used in Melania Trump's and Ivanka Trump's campaign speeches. From the modality used, the ideologies in the speeches can be revealed.

\section{Methodology}

The data analyzed in this study were the campaign speeches by Melania Trump and Ivanka Trump delivered on $19^{\text {th }}$ of July, 2016 in the Republican Convention Center to gain support for Donald Trump as one of the candidates of the United States president at that time. Stylistics, which aims to find out the purpose and effect from the use of certain linguistic (Verdonk, 2002: 4), was chosen as the approach of this study. By using stylistic approach, modality is seen as a feature which can show speakers' purpose or ideology.
Modality in stylistics is a feature which carries ideology.

To obtain all the data, sentential level of analysis was conducted to comprehend the meanings and level of the modality used. To continue to the deeper analysis of the function of modal towards the speakers' ideology, the types of modality were categorized. The types of modal were then ordered based on the percentages. After all the sentences containing modality were analyzed and described, the ideologies of the speeches were concluded.

\section{Findings and Discussion}

\section{The Types of Modality in Both Speeches}

The table below displays that there are 26 modals which exist in Melania Trump's campaign speech. In Ivanka Trump's campaign speech, there are 35 modals found. All of the type of modalities are employed by Ivanka Trump in her speech. Melania Trump employed all types of modality, except usuality. The two highest percentages of the types in both speeches are inclination and potentiality and ability. The inclination in Melania Trump's speech is $46.2 \%$, while in Ivanka Trump's is $31.5 \%$. The potentiality and ability in Melania Trump's speech is $38.4 \%$, whereas in Ivanka Trump's is $34.4 \%$. The two lowest percentages in both speeches are obligation and probability. The obligation and probability in Melania Trump's speech are both $7.7 \%$, while in Ivanka Trump's are $8.5 \%$ and $5.7 \%$. 
Table 1

The Types Modality in Both Speeches

\begin{tabular}{|l|c|c|c|c|}
\hline \multirow{2}{*}{ Types of Modality } & \multicolumn{2}{|c|}{ Melania Trump's Speech } & \multicolumn{2}{c|}{ Ivanka Trump's Speech } \\
\cline { 2 - 5 } & Number & Percentage & Number & Percentage \\
\hline Inclination & 12 & $46.2 \%$ & 11 & $31.5 \%$ \\
\hline Potentiality and Ability & 10 & $38.4 \%$ & 12 & $34.3 \%$ \\
\hline Usuality & - & - & 7 & $20 \%$ \\
\hline Obligation & 2 & $7.7 \%$ & 3 & $8.5 \%$ \\
\hline Probability & 2 & $7.7 \%$ & 2 & $5.7 \%$ \\
\hline Total & 26 & $100 \%$ & 35 & $100 \%$ \\
\hline
\end{tabular}

\section{a. Inclination}

The first type of modality found in the data is inclination. Both speeches have similar number of inclination. From the analysis, the level used in both speeches is high and the meaning inferred from the use is determination. The sentences below are examples taken from Melania Trump's speeches.

(1) I cannot or will not take the freedoms this country offers for granted.

(2) I know that he will make a great and lasting difference.

The modal used in (1) is will. This modal is included as high level of inclination because it shows determination. The verb that follows the modal is take. There is negation not in the sentence which means that Melania does not do the action to take the freedom from the country for granted. This sentence insists a commitment of future act not to take the freedom as something trivial. In fact, it is categorized as high level of inclination showing that Melania Trump seriously commits the act.

The modal which is used in (2) is will. This modal is categorized as high level of inclination. It shows a determination and is followed by the lexical item make. In (2), Melania expresses that she knows that he (Donald Trump) is the one who is going to change the America. The modal will is used to show Donald Trump's action towards
America in the future, which makes a great and lasting different. This is a high level of inclination because it shows determination or a strong willingness.

The sentences below are taken from Ivanka's speech whose modality is inclination.

(3) As president, my father will change the labor laws that were put into place at a time when women are not a significant portion of the workforce.

(4) And he will focus on making quality childcare affordable and accessible for all.

In (3), modal which is used is will. This modal is included in high level of inclination which reflects determination. This modal is followed by the verb change. This modal is used to explain the subject my father which refers to Donald Trump. Melania Trump, through this utterance, infers that Donald Trump strongly commits to change the labor laws if he becomes the president of the America.

The explanation for (4) is almost similar to (3). The modal which is used by Ivanka Trump in (4) is also will. This is also high level of inclination that reflects strong commitment or desire to do something. The modal in (4) is followed by verb focus. The subject of the sentence is he which refers to Donald Trump. From the lexical items mentioned before, it can be slightly concluded that Donald Trump commits to be 
focus. The following information is really needed to achieve the complete meaning. If it is seen in the whole context, Melania Trump tries to say that Donald Trump has strong desire to focus on making quality childcare affordable and accessible for all.

\section{b. Potentiality and Ability}

Both speeches also have similar modality. Those are categorized as high level of modality whose meaning is potential. Below are the examples taken from Melania Trump's speech.

(5) That will never change.

(6) There has to be plan for growth, only then will fairness result.

The potentiality can be caused by two reasons, human's ability and certain condition besides human involvement. In (5), the modal used is will. The modal is followed by verb change. However, there is a negation in the sentence as shown in the word never. It is understood based on the context, the lexical item that as the subject of the sentence refers to the previous phrase 'truly blessed'. By combining the modality, negation, and the verb, Melania Trump refers the feeling of being blessed is potentially not change at all.

In (6), the modal used is will. The verb that follows the modal is result. It is similar to the previous sentence that this modal is included in potentiality. This modality is categorized as high level of potentiality that can be seen from the whole meaning of the sentence. There are two clauses in one sentence. Both clauses are in cause and effect relationship. In (6), the first clause is the cause which is able to trigger something to happen. If there is a plan for growth, it can result the fairness. However, in the sentence, it can be seen that the modal is followed by the verb result. It can be concluded that the fairness is potentially resulted only if there is a plan for growth.

Sentences below are taken from Ivanka Trump's speech.

(7) And they would leave his office, as people so often do after having been with Donald Trump, feeling that life could be great again.

(8) He will ask them for their feedback, if they think something should be done differently or could be done better.

In (7), the modal which is used to show potentiality is could. The modal is followed by auxiliary verb be and an adjective great. The subject of the sentence is life. This sentence means that the officers are potential to feel that life is great again after they meet Donald Trump. By saying this, Ivanka Trump would like to say officers are potential to have a great life because of Donald Trump.

In (8), the modal which is used is could. The modal is followed by passive verb which is be done. The subject of the sentence is he which refers to Donald Trump. The sentence means that by asking the officers, Donald Trump will be able to know what is potential to be done better. In this case, the modal is used to express something that is potential to be done better.

\section{c. Obligation}

The sentences containing obligation in Melania Trump's speech are displayed as below.

(9) We should be satisfied with the stagnation.

(10) The has to be a plan for growth only then will fairness result.

In (9), the modal which is used is should. Based on the theory, this modal is included in mid-level of obligation which indicates something that is supposed to do. The modal is followed by auxiliary verb be and an adjective satisfied. However, there is a negation not in the sentence. The sentence means that the subject we is supposed to be unsatisfied with the stagnation. Supposed, based on the level of obligation, is a degree which is still negotiable. It is different if it is compared to the high level which insists something obligatory. The example of high level of obligation can be seen in (10). 
In (10), modal adverb has to is employed. This modal is categorized in high level of obligation which means something that cannot be negotiated. In the other words, it can be insisted as a must. The modal is followed by auxiliary verb be and a noun phrase a plan. Melania Trump refers that a plan is a must in order to achieve the fairness. In the other words, Melania Trump infers that the fairness will be achieved only if there is plan for that.

Below are the examples of obligation found in Ivanka Trump's campaign speech.

(11) He will ask them for their feedback, if they think something should be done differently or could be done better.

(12) Policies that allow women with children to thrive should not be novelities.

The modality which is used in (11) is should. This modality is included in mid-level of obligation. Since it is included in mid-level, this modal means supposed. The sentence has he as the subject of the sentence which contextually refers to Donald Trump. The verb that follows the modal is a passive verb be done. The purpose of Ivanka by uttering this sentence is to show that Donald Trump always asks them (the officers) for feedback. This has a purpose to see whether there is something that is supposed to be done differently.

Sentence (12) has similar modal, should. This belongs to the mid-level of obligation which means supposed. There is an auxiliary verb that follows the modal, which is be, and the noun novelties. However, there is a negation not in the sentence which, in this case, shows something that cannot be done. Ivanka Trump utters the sentence to argue that the policies that allow women with children to thrive are not supposed to be novelties. In the other words, it has to be a tradition and something in common.

\section{d. Probability}

There are only two sentences in Melania Trump's speech which contain probability. Based on the theory, probability is the condition or state when something possibly happens. Below are the sentences.

(13) The race will be hard-fought, all the way to November.

(14) There will be good times and hard times and unexpected turns.

The modal type probability in (13) is will. In that sentence, will is included in mid-level. The modal is used to show something that probably happens. Melania Trump predicts that all the way to November is probably hard-fought. This modal is used because Melania Trump can be unsure about the future condition. Nevertheless, she still has belief that it will be hard-fought.

This explanation is also able to be applied in the last example, (14). The modal used is also will. This modal is also included in mid-level of probability. Melania Trump uses this modal to express her belief that in the future, there exists good times, hard times, and unexpected turns. However, it is still appropriate to be called as a prediction because Melania Trump is still unsure about something that may happen in the future time. That is, why this modal is included in mid-level type of probability.

The examples of probability found in Ivanka Trump's campaign speech are as follows.

(15) Words and promises, no matter visionary they sound will only get you so far.

(16) Floor by floor a soaring structure will appear, usually record breaking in its height and iconic in its design.

Both sentences use modal will to show the notion of probability. Both modals also have a mid-level of probability. In (15), the modal is followed by verb get. Then, the subject of the sentence is words and promises no matter visionary they sound. The implied meaning that is tried to be delivered by Ivanka Trump is that the words in the form of promises and visionary from other candidates probably make you far away from the reality. Those promises and visionary are only novelties. 
In (16), the modal is followed by the verb appear. The subject of the sentence in (16) is a soaring structure. The function of modality in the sentence is to show that soaring structure of a tower is probable to appear. In addition, Ivanka Trump adds that the tower is usually record breaking in its height and iconic in its design.

\section{e. Usuality}

Usuality only appears in Ivanka Trump's speech. Below are the sentences.

(17) He would talk to them and then draw upon his extensive network to find them a job or get them a break.

(18) And they would leave his office, as people

so often do after having been with

Donald Trump, feeling that life could be greater again.

The modal employed in (17) is would. This modal is a mid-level modal of usuality. The subject of this sentence is he referring to Donald Trump. The verb talk follows the modal. That sentence means that Donald Trump usually talks to them. If it is seen from the whole context, the word them refers to the people who experience injustice and hardship.

Sentence (18) has similar explanation to (17). The modal would is also a mid-level of usuality. However, sentence (18) has different subject of sentence, they. The personal pronoun they refers to the people who experience injustice and hardship. The modal in this sentence tells us that after they meet Donald Trump, they usually feel relief and believe that life could be great again.

\section{Ideologies Reflected from the Use of Modality}

a. Commitment

The first ideology, commitment, is shown from the use of inclination. There are 12 inclinations found in Melania Trump's campaign speech. In the result of the first objective, it is found out that inclination is the most frequent type of modality used by the speaker. The percentage is $46,2 \%$. Nine of inclinations found are categorized as high level inclination. It has been mentioned that this level shows determination.

It is assumed that the use of determination reveals commitment. The sentences that contain the high level of inclination reflect the commitment of both the speaker and the personal pronoun he which contextually refers to Donald Trump. The sentence below shows commitment.

(19) I cannot or will not, take the freedoms this country offers for granted.

The sentence above has $I$ as the subject referring to Melania Trump. From the use of modality, it can be seen that the speaker tries to express her commitment not to take the freedom the country offers for granted. Thus, it is obvious that the use of that modality is to reflect the speaker's commitment.

In the data, the speaker also uses the high level of inclination in other sentences. It is found that the speaker uses the modality to show Donald Trump's commitment as a candidate of the president. It is shown from the use of personal pronoun for the subject of the sentences such as he, my husband, and Donald. This argument is proven by some of the sentences containing high level inclination as provided below.

(20) He will never, ever, give up.

(21) He will never, ever, let you down.

(22) And he will do this better than anyone else can.

From those examples, it can be seen that all of the sentences use personal pronoun he as the subject. Contextually, the personal pronoun he refers to Donald Trump. All of the sentences above also use high level modal of inclination to show determination. In (20), the speaker tries to tell the audiences that Donald Trump determines to never give up. It means that he commits to struggle. In (20), the speaker still uses similar subject and level of inclination. Melania Trump says that Donald Trump commits to never let you down. You, in this context, refers to the audiences, who are all Americans. 
In (21), the subject is he and the modal used is still similar to the previous one. Melania Trump mentions that Donald Trump determines to do this better than anyone else. This, in this sentence, is the replacement of acts he will execute in the future time towards America. From the use of modality, it can be concluded that Melania Trump shows the commitment that Donald Trump will execute the acts better than any other candidates.

In other sentences, it is also found out that high level inclination is used to show commitment of both Melania Trump and Donald Trump. As a wife of a president candidate, it can be seen that Melania Trump tries to show her involvement in Donald Trump's mission. The high level inclination is also employed by Melania Trump to show her commitment which is shown in the sentence below.

(23) We must do our best to ensure that every

child can live in comfort and security, with the best possible education.

(24) These are the values Donald and I will bring to the White House.

The subject in (23) is we. The subject obviously refers to Melania Trump and Donald Trump. The subject in (24) is also Donald Trump and I. The sentences above use high level of inclination. In (23), the speaker states that Melania Trump and Donald Trump determine to do the best. It shows their commitment to ensure that every child can live in comfort and security. In (24), the speaker asserts that they have the values they determine to bring.

In Ivanka Trump's speech, there are nine sentences which contain inclinations. They are categorized as high level. High level of inclination expresses determination. From all of the sentences applying high level of inclination, it is revealed that eight sentences have the subject he referring to Donald Trump. It can be said that Ivanka Trump tries to tell the audiences about Donald Trump's commitment. The examples are provided below.

(25) As president, my father will change the labor laws that were put into place at a time when women were not a significant portion of the workforce.

(26) He will fight for equal pay for equal work.

In (25), Ivanka Trump says that her father, Donald Trump, determines to change the labor laws if he is elected as the president. The determination shows a strong desire that can also be called as a commitment to change the labor law. In (26), Ivanka Trump also uses the modality to tell the determination of the subject he. In this sentence, Ivanka Trump says that Donald Trump determines to fight for equal pay and work. This modal is a high level of inclination. This sentence shows that Donald Trump commits to fight for the equal pay and work for all of Americans.

The employment of high level of inclination is to express Donald Trump's commitment. However, there is a sentence found in the speech that the high level of inclination is also used to express the speaker's commitment. It can be seen from the sentence that uses subject $I$ and employs high level of inclination. The sentences are provided below.

(27) And I will fight for this too, right along side of him.

The sentence above reveals that the speaker determines to fight alongside of him (Donald Trump). This shows her commitment also to fight for equal pay and equal work. To sum up, the high level of inclinations is employed to project the speaker's and also Donald Trump's commitment.

\section{b. Self-Promotion}

The other ideology reflected by the use of modality in Melania Trump's campaign speech is self-promotion. Political speech is strongly related to how to affect the people to vote. This has a purpose to influence the 
result of an election. This is also what is done by Melania Trump.

Melania Trump delivers the speech as a form of campaign. Starting from this point, one of the ideologies reflected from the use of modality is self-promotion. Commonly, people will tell something good about them to build trust for others. In this case, it is seen that Melania Trump employs potentiality and ability to influence the audiences.

Based on the previous discussion. It is found out that there are 10 sentences using potentiality and ability. The percentage is $38,4 \%$. This number is quite considerable. This type of modality has significant role to influence the audience. The explanation of the argument is provided in some of the examples below.

(28) And I can assure you, he is moved by this great honor.

(29) Donald is the only one that can deliver it.

Modality in (28) reveals the notion of ability. This modality is used to show the ability of the subject $I$ which refers to the speaker. The modal emphasizes the ability to assure you, referring to the audiences. The verb assure in the sentence expresses how Melania Trump is very certain of what she says. Melania Trump is sure that Donald Trump is moved by his great honor. By uttering this sentence, Melania Trump tries to inform the audiences that Donald Trump is moved by something good, great honor. It is, then, expected that people will vote the best person. Thus, the notion of self-promotion can be seen through good quality figure that is projected by the speaker by telling good values of Donald Trump to the audiences.

This also happens in sentence (29). Melania Trump says that Donald Trump is the only one who is able to deliver it. This sentence also shows that Donald Trump is the most proper person to lead America. It can be seen from the speaker's utterance that Donald Trump is the only one who is able to deliver it. This short sentence reveals that Melania Trump tries to promote Donald Trump by telling the ability. By doing so,
Americans will choose him. Thus, it can be concluded that the type of potentiality and ability emphasize self-promotion.

Ivanka Trump's speech also contains the same ideology as Melania Trump's. Selfpromotion becomes the ideology because there are 12 sentences contain potentiality and ability in the speech. It is also already explained in the previous part that potentiality and ability reflect self-promotion because one of the purposes of political speech is influencing people's perspective.

Potentiality and ability show someone's skill (ability) and the effect of having the skill (potentiality). In Ivanka Trump's speech, the number of percentage of potentiality and ability is the highest among other types. It is $34.3 \%$. The employment of potentiality and ability does not merely aim to inform the audiences about the speaker's and Donald Trump's skill or ability. However, Ivanka Trump tries to make the audiences know that Donald Trump and her have the capability. By uttering the sentences containing potentiality and ability, Ivanka Trump shows that Donald Trump is capable to be the president. The proofs are provided below.

(30) My father not only has the strength and ability necessary to be our next president, but also the kindness and compassion that will enable him to be the leader that this country needs.

In (30), the speaker employs modality to show potentiality. Potentiality exists because of Donald Trump's ability for having such strength that enables him to be the leader. This sentence shows that Ivanka Trump tries to promote his father as someone who has the ability.

The last type of modality that can reveal the ideology of self-promotion is usuality. It is found out that $20 \%$ of all types of modality are categorized as. Based on the sentences, the speaker employs this type of modality to show Donald Trump's habit. Most of the habits talk about how Donald Trump treats his employee. It can be seen from these sentences. 
(31) He would talk to them and then draw upon his extensive network to find them a job or get them a break.

(32) On every one of his projects, you will see him talking to the super, the painter, the engineers, the electricians.

(33) He will ask them for their feedback, if they think something should be done differently or could be done better.

All the example of usuality mentioned above are included as mid-level. This level of usuality already shows something which is done regularly. In the other words, this level already shows Donald Trump's habit. Of course the high level of usuality will show more frequent intensity.

In sentence (31), Ivanka Trump tries to show the audiences about her father's habit that he usually talks to the jobless people and helps them to get a job. This sentence shows his concern about others who need helps. In (32), Ivanka Trump tries to say that in every Donald Trump's project, he usually talks to the super, the painter, and any other workers. This sentence shows that Donald Trump usually pays attention to his project. He is responsible for his own plan. In (33), Ivanka Trump tries to show the audience that Donald Trump usually asks the worker about the project. It means that Donald Trump is not a dictator. He puts his employee's suggestion, opinion, and thought in mind.

The notion of self-promotion is still the same. Ivanka Trump tries to give a good projection of Donald Trump. She tells the audiences that Donald Trump usually helps jobless people. This sentence implies the meaning that Donald Trump is down to earth and kind hearted. She also shows how Donald Trump deals with every plan of his projects. It implies meaning that Donald Trump will do the same if he becomes the president. Ivanka Trump also shows that Donald Trump always hears the voice of the employee. It implies that he will listen to Americans if he is chosen as the president. He will not be a dictator.

All of the explanations above demonstrate that Ivanka Trump promotes her father. Ivanka Trump shows the good sides of her father by employing usuality to show his good habit towards lower people and project. In fact, usuality is used only to tell about his father. Thus, $20 \%$ is also a reasonable number to express selfpromotion as the ideology found in the speech.

\section{Conclusion}

The analysis shows that there are four types of modality in Melania Trump's campaign speech. Those are inclination, obligation, potentiality and ability, and probability. The modal of inclination appears 12 times. It is $46.2 \%$. There are nine high levels, two mid-levels, and one low level of inclination. The modal of obligation and probability appears twice, presented in $7.7 \%$. In obligation, one sentence is included as high level and another one is included in mid-level. All of the probabilities are included as midlevel. The last, potentiality and ability appear 10 times, presented in $38.4 \%$.

On the other hand, there are five types of modality in Ivanka Trump's campaign speech. Those are inclination, usuality, potentiality and ability, probability, and obligation. There are 11 sentences containing inclination in the speech. The percentage is $31.5 \%$. Nine of the inclinations are categorized as high level and the rest are as mid-level. There are 12 sentences with potentiality and ability. The percentage is $34.3 \%$. Usuality occurs seven times. There are two modality included as high level of usuality and the other five are categorized as mid-level. The percentage of this type is $20 \%$. The next is obligation. It occurs three times, presented in $8.5 \%$. Two of obligations are included as mid-level and another is low level. The last type is probability. It occurs only twice. The percentage of this type is $5.7 \%$, categorized as mid-level.

The employment of certain types of modality above reveals that both speakers project the same ideologies. Commitment is the first ideology in both speeches, seen from the use of inclination. The high level meaning of inclination found in the data display that 
both speakers assure the audiences about Donald Trump's promise. The second ideology, self-promotion is shown by other types of modality. Potentiality-ability and usuality reveal that both speakers promote Donald Trump's capability and habit.

\section{References}

Akmajian, Adrian, Richard A, Demers, Ann K. Farmer, Robert M. Harnish. Linguistics: An Introduction to Language and Communication. London: The MIT Press. 2001.

Bayram, Fatih. Ideology and Political Discourse: A Critical Discourse Analysis of Edorgan's Political Speech. Vol. 7. (2010): p. 23-40. ARECLS. November 23, 2016.

Best, John W., James V. Kahn. Research in Education. Boston: Pearson. 2016

Bybee, Joan, Revere Perkins, and William Pagliuca. The Evolution of Grammar: Tense, Aspect, and Modality in the Language of the World. Chicago: The University of Chicago Press. 1994.

Crawford, Hillary E. Transcript of Melania Trump's RNC Speech Shows a Side of Her America Has Yet to See. n.p. July 19, 2016. (bustle.com/articles/173441-transcript -of-melania-trumps-rnc-speech-showsa-side-of-her-america-has-yet-to-see). October 3, 2016.

Downing, Angela. English Grammar: A University Course. New York: Routledge. 2015

Drabold, Will. Read Ivanka Trump's Speech at the Republican Convention. n.p. July 22, 2016. (time.com/4417579/republicanconvention-ivanka-trump-transcript/). November 10, 2016.

Gee, James Paul. An Introduction to Discourse Analysis: Theory and Method. New York: Routledge. 2011
Halliday, M.A.K. and Matthiesen, Christian M.I.M. An Introduction to Functional Grammar: $3^{\text {rd }}$ Edition. London: Hodder Education. 2004

Hillier, Hilary. Analysing Real Texts: Research Studies in Modern English Language. New York: Palgrave Macmillan. 2004

Horn, Laurence R. and Gregory Ward. The Handbook of Pragmatics. Oxford: Blackwell Publishing Ltd. 2006.

Isti'anah, Arina. "Ideology in Hosni Mubarak's and Muammar Qaddafi's Translated Speeches: Critical Discourse Analysis". Thesis. Yogyakarta: Sanata Dharma University. 2012

Lillian, Donna. L. "Modality, Persuassion and Manipulation in Canadian Conservative Discourse". Critical Approaches to Discourse Analysis across Disciplines. Vol. 2. No. 1: p. 1-16. East Carolina University. (cadaad.org/e-journal). October 7, 2016. 2008

Lock, Graham. Functional English Grammar: An Introduction for Second Language Teacher. New York: Cambridge University Press. 1996

Locke, Terry. Critical Discourse Analysis. New York: Continuum International Publishing Group. 2004

Nunan, David. Introducing Discourse Analysis. London: Penguin Books. 1993

Olanian, Kazeem K., Adelou, Adeniji. "Modality in Statement of Objectives in Art-Based Research Article Abstract" BritishJournal of English Linguistics. Vol.3. No.1 (2015): p. 42-51. European Centre for Research Training and Development UK (eajournals.org). November 22, 2016.

O'Grady, William, Michael Dobrovolsky, Francis Katamba. Contemporary Linguistics: An Introduction. London: Longman. 1996

"Political Speech". Renew Democracy. n.p. November 7, 2011. (renewdemocracy. org/blog/posts/435/Political-Speech). January 18, 2017. 
Simpson, Paul. Language, Ideology, and Point of View. New York: Routledge. 2004

Simpson, Paul. Stylistics: A Resource Book for Student. London: Routledge. 2004

Toolen, Michael. Language in Literature. London: Routledge. 1998

Verdonk, Peter. Stylistics. Oxford: Oxford University Press. 2002 